ISSN 2693-2458

COVID -19 and Cardio Metabolic Practice at MENA Regions. Policy Analysis \& Recommendations

\title{
Journal of Diabetes and Endocrinology Research
}

Research Article

Abdalla Abotaleb

WHO Project Manager Health policy analysis expert, MENA

*Correspondence author

Network for Biologicals Stakeholders founder

\author{
Abdalla Abotaleb PhD \\ WHO Project Manager Health policy analysis expert \\ MENA Network for Biologicals Stakeholders founder \\ Egypt
}

Submitted : 6 Oct 2020 ; Published : 15 Nov 2020

\begin{abstract}
Health systems were not expected COVID -19 pandemic which made Pressure on that systems. Practice at Cancer field had different nature at COVID -19. Due to the following (patients type, Diagnosis Process and patient journey) the objective of this research is finding out impact of COVID -19 on cardio metabolic practice.

Methods: Integration analysis between International guidelines like (ESC, NHS, WHO) and conducting local survives with local Physicians at previous countries.

Results: Periodization criteria was very influencer at practice elements this leaded to medications plans changing through different solutions one of those solutions was health technologies

Conclusion: Dynamic prioritization criteria was founded the corner stone for Practice adaption for Safety enhancement through Time reducing plans managed Effective leadership elements through technology solutions .
\end{abstract}

\section{Objectives}

Pandemicity of COVID- 19 was not expected from any health systems it did not matter if those systems were strong or weak that Pandemicity developed various responses from different specialties. The objectives of this research is analyze impact of COVID -19 on Cardio metabolic practice at MENA countries (Algeria, Morocco, Egypt, Lebanon, KSA, UAE and Turkey) to find out recommendations

\section{Methods}

Integration analysis between International guidelines like (ESC, NHS, WHO) and conducting local survives with local oncologist at previous countries.

One way sensitivity analysis was conducted for all parameters affecting on practice adaptation to ensure validity and accuracy.

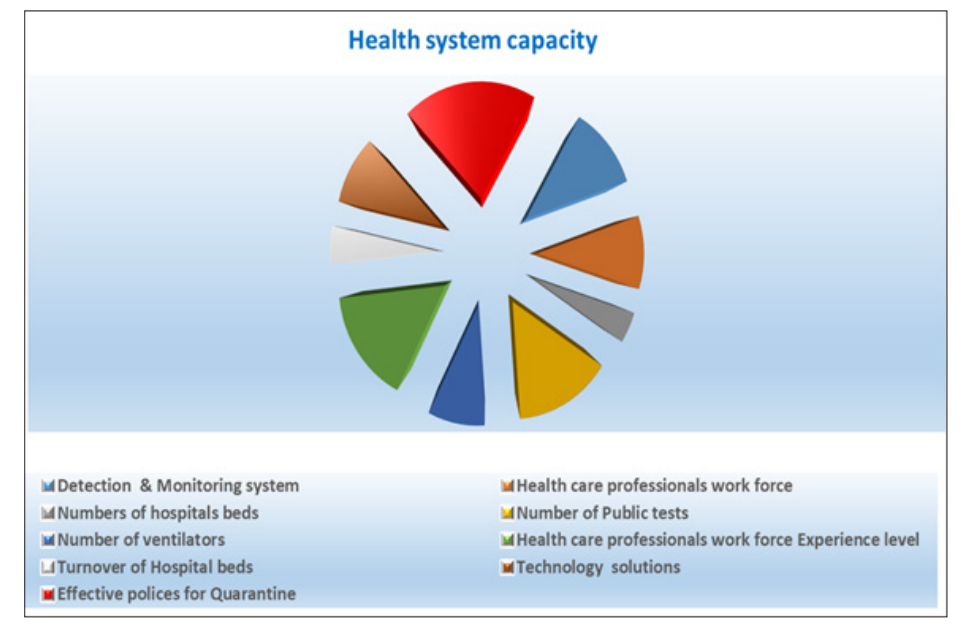




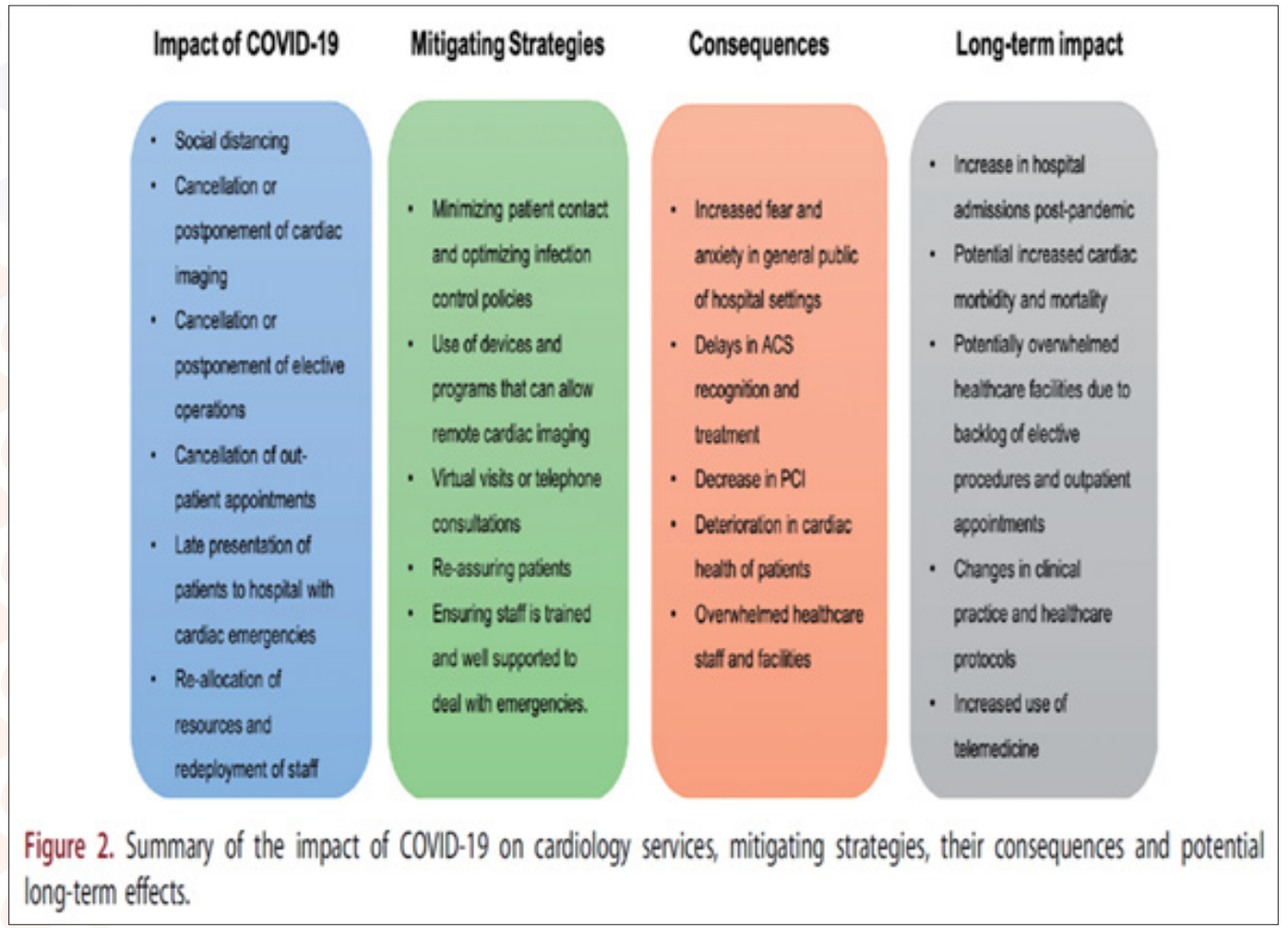

Results

The following results were found
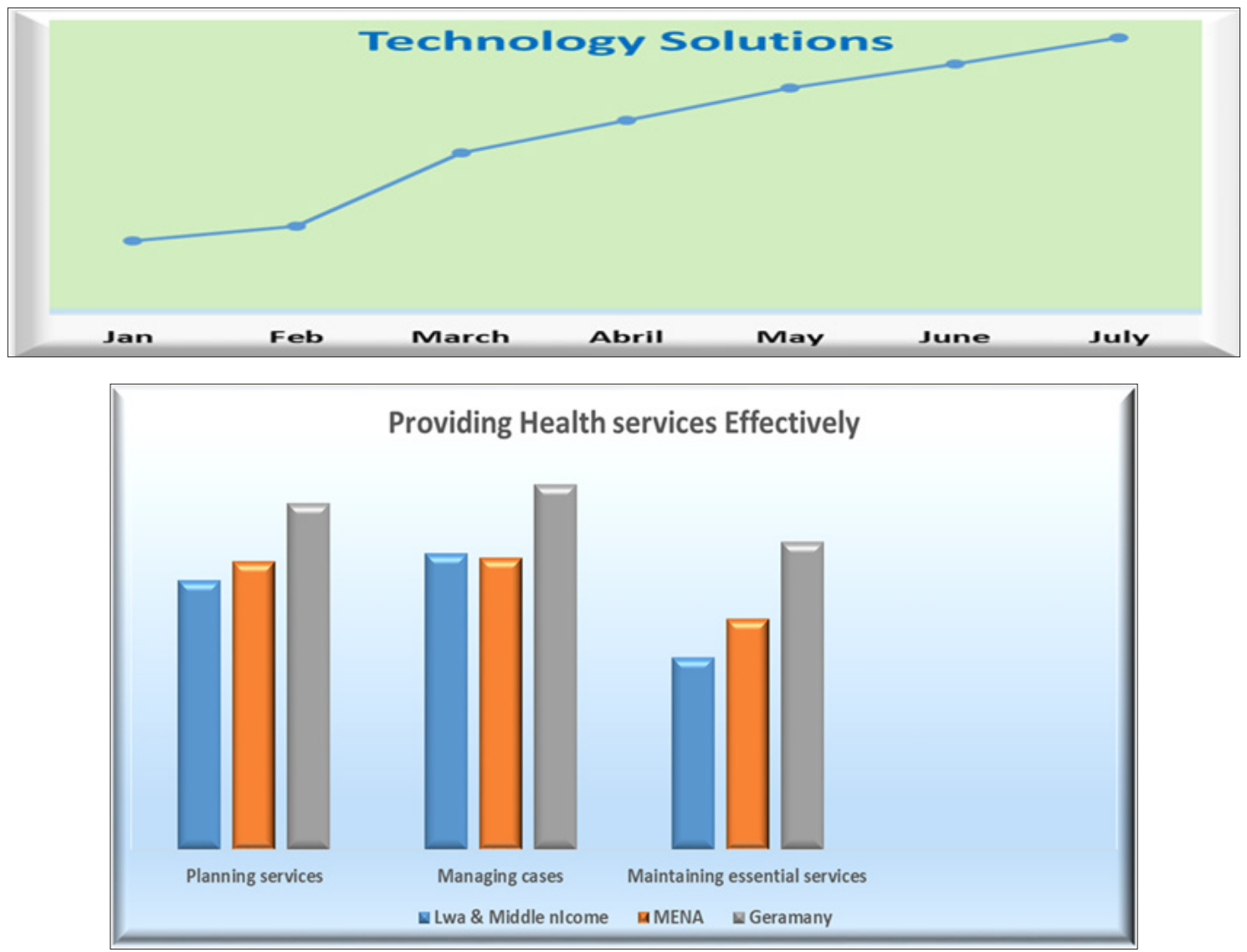

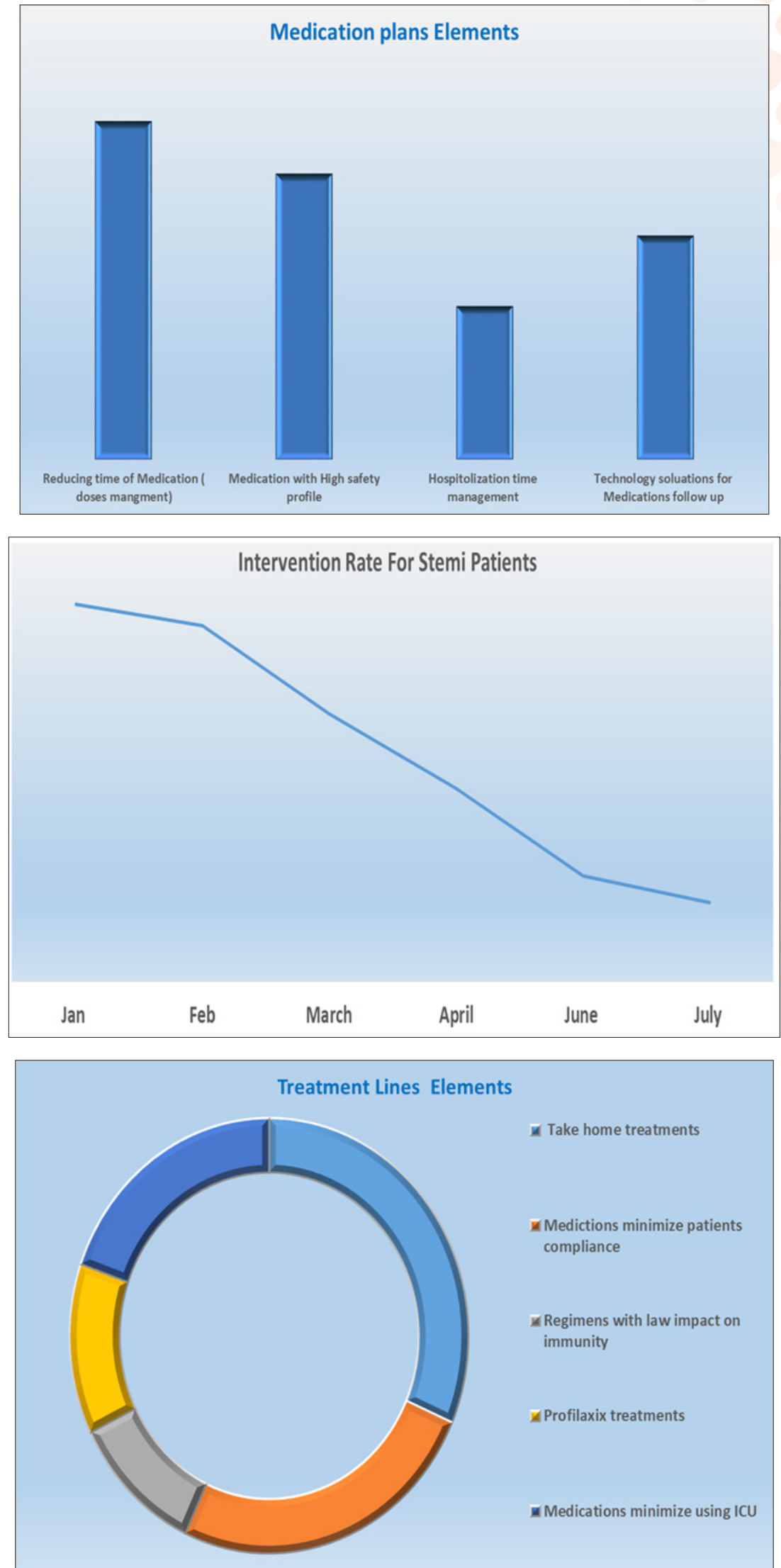

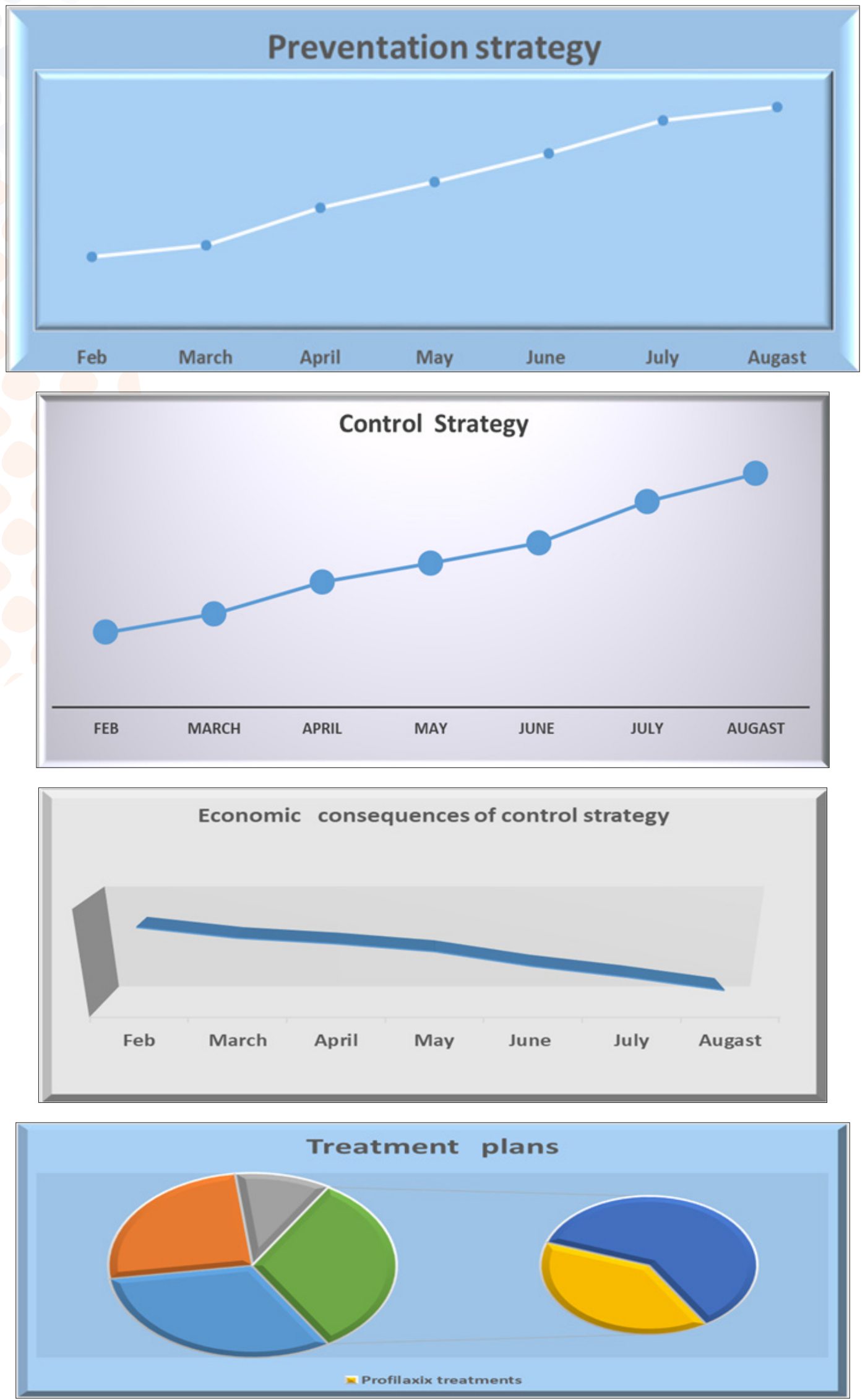

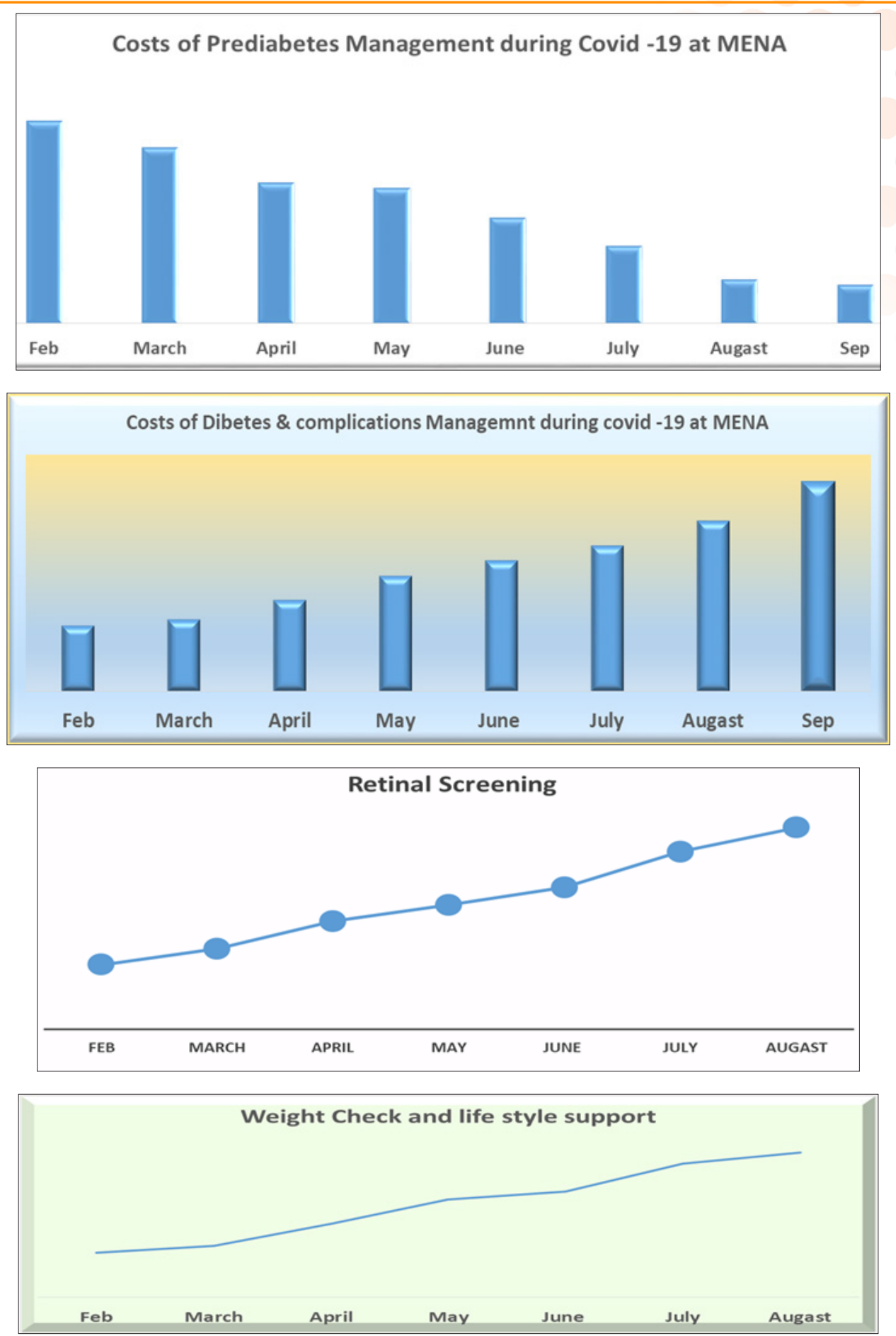

\section{Discussion}

One of the major challenges faced medical society during COVID -19 pandemic is capacity of medical practice to adapt during this crisis. This Research analyzing the Cardio metabolic practice adaption during COVID -19 pandemic and what were the major Elements for that adaptation for giving recommendations to all stake holders at medical field about how practice and system response to pandemic case in order to share knowledge to enhance system performance.
- 19 Pandemicity Should take into considerations Dynamic prioritization criteria plans the objective of these plans is Reducing time for service which will lead to enhance safety for patients and oncologists. And the reducing time objectives changed medication plans and all the previous elements achieved through Effective leadership elements plus technology solutions [1-8].

\section{Conflict of Interest}

No conflict of interest

\section{Conclusion}

Effective practice adaptation in oncology field during COVID 


\section{References}

1. Who.int. 2020 [Accessed 2020 Jun 8]. Available from: https://www.who.int/docs/default-source/coronaviruse/situation-reports/20200606-covid-19-sitrep-138. pdf?sfvrsn=c8abfb17_4.

2. Li B, Yang J, Zhao F, et al. (2020) Prevalence and impact of cardiovascular metabolic diseases on COVID-19 in China. Clin Res Cardiol 109(5): 531-538.

3. Long B, Brady W, Koyfman A, et al. (2020) Cardiovascular complications in COVID-19. Am J Emerg Med 38(7): 15041507.

4. Garcia S, Albaghdadi M, Meraj P, et al. (2020) Reduction in ST-segment elevation cardiac catheterization labora- tory activations in the United States during COVID-19 pandemic. J Am Coll Cardiol 75(22): 2871-2872.

5. Tam C, Cheung K, Lam S, et al. (2020) Impact of Coronavirus Disease 2019 (COVID-19) outbreak on ST-segment-elevation myocardial infarction care in Hong Kong. Circ Cardiovasc Qual Outcomes 13(4): 1-3.

6. Zhou F, Yu T, Du R, et al. Clinical course and risk factors for mortality of adult inpatients with COVID-19 in Wuhan, China: a retrospective cohort study. The Lancet 395(10229): 1054-1062.

7. Skulstad H, Cosyns B, Popescu B, et al. (2020)COVID-19 pan- demic and cardiac imaging: EACVI recommendations on precautions, indications, prioritization, and protection for patients and healthcare personnel. Eur Heart J Cardiovasc Imaging 21(6): 592-598.

8. Escardio.org. ESC Guidance For The Diagnosis And Management Of CV Disease During The COVID-19 Pandemic; 2020 [Accessed 2020 Jun 8]. Available from https://www.escardio.org/Education/COVID-19-andCardiology/ESC-COVID-19-Guidance\#p06.
Copyright: (C2020 Abdalla Abotaleb. This is an open-access article distributed under the terms of the Creative Commons Attribution License, which permits unrestricted use, distribution, and reproduction in anymedium, provided the original author and source are credited. 